\title{
Peroxidase gene discovery from the horseradish transcriptome
}

\author{
Laura Näätsaari ${ }^{1}$, Florian W Krainer ${ }^{1}$, Michael Schubert ${ }^{1,3}$, Anton Glieder ${ }^{2}$ and Gerhard G Thallinger ${ }^{2,3^{*}}$
}

\begin{abstract}
Background: Horseradish peroxidases (HRPs) from Armoracia rusticana have long been utilized as reporters in various diagnostic assays and histochemical stainings. Regardless of their increasing importance in the field of life sciences and suggested uses in medical applications, chemical synthesis and other industrial applications, the HRP isoenzymes, their substrate specificities and enzymatic properties are poorly characterized. Due to lacking sequence information of natural isoenzymes and the low levels of HRP expression in heterologous hosts, commercially available HRP is still extracted as a mixture of isoenzymes from the roots of A. rusticana.

Results: In this study, a normalized, size-selected A. rusticana transcriptome library was sequenced using 454 Titanium technology. The resulting reads were assembled into 14871 isotigs with an average length of $1133 \mathrm{bp}$. Sequence databases, ORF finding and ORF characterization were utilized to identify peroxidase genes from the 14871 isotigs generated by de novo assembly. The sequences were manually reviewed and verified with Sanger sequencing of PCR amplified genomic fragments, resulting in the discovery of 28 secretory peroxidases, 23 of them previously unknown. A total of 22 isoenzymes including allelic variants were successfully expressed in Pichia pastoris and showed peroxidase activity with at least one of the substrates tested, thus enabling their development into commercial pure isoenzymes.

Conclusions: This study demonstrates that transcriptome sequencing combined with sequence motif search is a powerful concept for the discovery and quick supply of new enzymes and isoenzymes from any plant or other eukaryotic organisms. Identification and manual verification of the sequences of 28 HRP isoenzymes do not only contribute a set of peroxidases for industrial, biological and biomedical applications, but also provide valuable information on the reliability of the approach in identifying and characterizing a large group of isoenzymes.
\end{abstract}

Keywords: Horseradish peroxidase, Armoracia rusticana, Transcriptome sequencing, Pichia pastoris, 454 sequencing

\section{Background}

Horseradish peroxidases (HRPs) originating from the perennial herb Armoracia rusticana (Brassicaceae) are heme-containing monomeric glycoproteins belonging to the class III plant peroxidase subfamily [1]. These versatile enzymes have traditionally been utilized as reporters in various diagnostic assays and histochemical stainings but have also gained increasing interest in other life science and biotechnological applications ranging from cancer therapeutics [2], protein engineering [3] and transgenics [1] to bioremediation [4], biosensors [5] and biocatalysis

\footnotetext{
* Correspondence: gerhard.thallinger@tugraz.at

${ }^{2}$ Austrian Centre of Industrial Biotechnology (ACIB GmbH), Petersgasse 14, 8010 Graz, Austria

${ }^{3}$ Institute for Genomics and Bioinformatics, Graz University of Technology, Petersgasse 14, 8010 Graz, Austria

Full list of author information is available at the end of the article
}

[6]. The in vivo functions of HRPs have not been fully elucidated owing to the estimated large number of isoenzymes (up to 42) [7], but are known to be very diverse [8] thus offering a wide range of substrate specificities and applications. Although HRP has been studied for decades and in spite of the large diversity of this enzyme family, protein engineering and heterologous expression have mainly been focused on one single isoenzyme $\mathrm{C} 1 \mathrm{~A}$, thus neglecting the potential of all others. This was largely due to the lack of sequence information and the low efficiency of HRP expression in heterologous hosts. Commercial preparations are still extracted from the roots of $A$. rusticana and therefore consist of a mixture of various isoenzymes. The quality of these preparations varies greatly and depends on several biotic and abiotic factors, such as seasonal change or origin. Chromatographic purification 
is needed to isolate highly enriched isoenzyme fractions. Only very few purified isoenzymes were accessible so far and their substrate specificities and enzymatic properties are poorly characterized.

The sequences of only eight isoenzymes are currently known: six nucleotide sequences $(\mathrm{C} 1 \mathrm{~A}, \mathrm{C} 1 \mathrm{~B}, \mathrm{C} 1 \mathrm{C}, \mathrm{C} 2$, $\mathrm{C} 3, \mathrm{~N})$ have previously been published [9-11] and two amino acid sequences A2 (P80679) [12] and E5 (P59121) [13] have been determined. However, for decades, HRP has been known as a large group of enzymes with versatile physical properties. Already in 1966, Shannon et al. [14] described the physical properties of seven isoenzymes. Aibara et al. $[15,16]$ characterized five neutral isoenzymes (B1, B2, B3, C1 and C2) and six basic isoenzymes (E1-E6) in 1982 and 1981, respectively. A total number of 42 peroxidase isoenzymes have been identified by isoelectric focusing in commercially available HRP preparations [7], without knowing whether these isoenzymes differ in amino acid sequence or due to different post-translational modifications.

This study has two major goals. First, we resolve the transcriptome sequence of $A$. rusticana, a perennial plant of industrial and medical importance. The availability of a large expressed sequence tag (EST) collection is crucial to support annotation in possible future $A$. rusticana genome sequencing projects. Secondly, we demonstrate the use of an efficient enzyme discovery pipeline including new generation cDNA sequencing technologies, in silico isoenzyme discovery and experimental sequence verification, gene synthesis and enzyme production and secretion by Pichia pastoris (Komagataella pastoris) as a straightforward approach to discover and characterize new isoenzymes from plants or other eukaryotes. Transcriptomes deliver all sequences of expressed genes, at the same time avoiding sequencing introns and providing information about all expressed exons and alternative exon junctions. Studies in Arabidopsis thaliana, a model species of the Brassicaceae family, have demonstrated the power of massively parallel transcriptome sequencing in providing high-quality representation of transcripts needed for gene discovery [17]. Similar transcriptome sequencing approaches have previously been applied, for example, in marker development, population genomics [18] and predictions of biosynthetic pathways [19-23]. Over the course of the study, the new 'third-generation' and 'fourth-generation' sequencing techniques have revolutionized the speed and cost of the transcriptome sequencing projects [24]. Hundreds of transcriptomes have been sequenced and annotated, especially by the large sequencing projects $1 \mathrm{KP}$ [25-27], PhytoMetaSyn [28,29] and Medicinal Plant Genomics Resource [30,31]. However, the concept of novel isoenzyme discovery from the large bulk of sequences generated by next generation sequencing (NGS) technologies needs a full pipeline of efficient tools. This is the first study using NGS transcriptome sequencing to discover, discriminate and characterize large numbers of sequence verified isoenzymes of non-model plant origin. Although a similar study was recently performed to identify fungal cellulases [32], the method described utilized combined secretome and transcriptome analyses and was only aiming to show cellulose activity of the cloned cDNA without the need of the full verified sequences to make all discovered isoenzymes available by recombinant expression. The method described in this study can be widely applied for the replenishment of the sequence data in any eukaryotic organism including fungi, plants and animal cell lines or tissues when detailed sequence and gene structure information of enzymes and isoenzymes is needed.

\section{Results}

\section{Sample preparation and CDNA library generation}

The high quality (RNA integrity number RIN 9.4-9.8) of the RNA samples was confirmed with an Agilent 2100 bioanalyzer. In order to include the majority of all encoded isoenzymes, a mixture of RNA from diverse plant parts, including leaves, roots, sprouts and stems, was chosen for mRNA isolation. cDNA synthesis, normalization, size selection and cloning was performed by LGC Genomics (Berlin, Germany). The normalized cDNA library was subjected to quality control experiments before using it for 454 pyrosequencing: a cDNA fragment size of over 800 bp was ensured and the normalization efficiency was verified by sequencing 96 randomly selected clones (LGC Genomics).

\section{Sequencing and de novo assembly}

The normalized cDNA library was sequenced on half a picotiterplate run on the GS FLX using Roche 454/ Titanium chemistry. A total of 592507 sequence reads with an average read length of $353 \pm 122$ nucleotides were obtained. A total of 12798 (2.16\%) clonal reads (exact, 3' or 5') were detected. Prior to assembly, the sequence reads were screened for the linker sequence used for concatenation, the linker sequences were clipped and the reads were quality checked (LGC Genomics). The resulting 556269 reads with an average length of $343 \mathrm{bp}$ (Figure 1A) were further filtered by Newbler sequence filtering to ensure consistent high quality of the reads used in the assembly. 490285 reads were aligned to individual transcripts using Newbler version 2.5.3 with default settings. The de novo assembly generated 18511 contigs with an average length of $718 \mathrm{bp}$ (Figure 1B) and an average coverage of 11.4-fold (Figure 1C). The contigs were further processed to 14871 isotigs with an average length of $1133 \mathrm{bp}$ (Figure 1D). 35950 reads were left as 


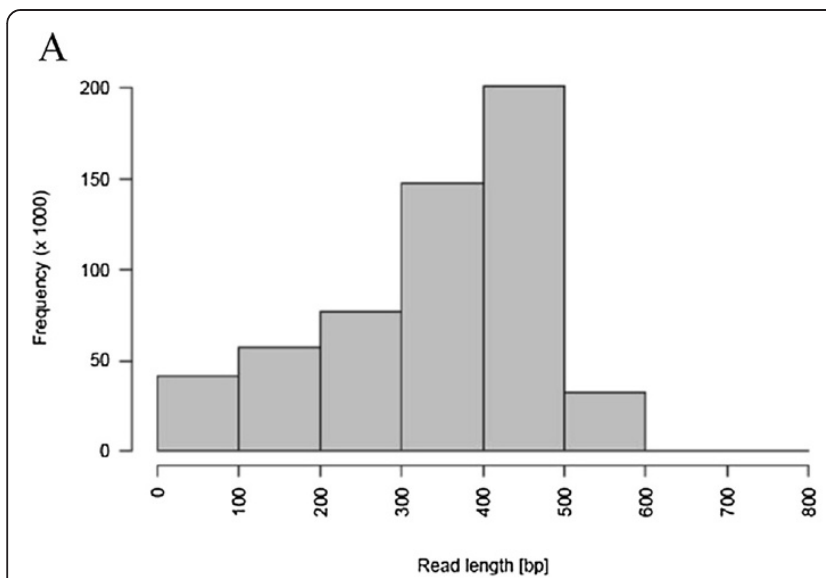

$\mathrm{C}$

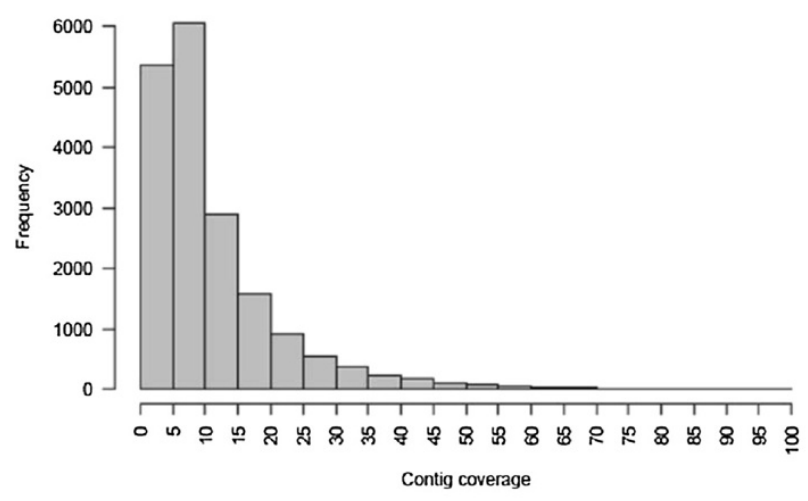

B

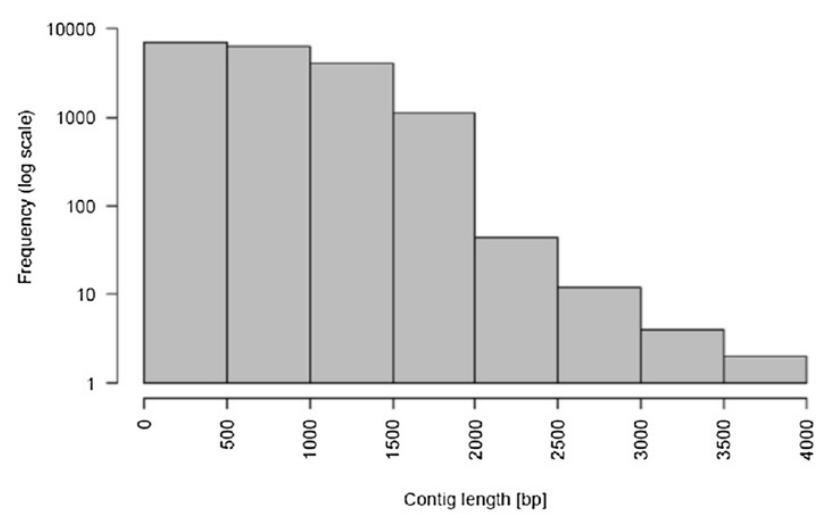

$\mathrm{D}$

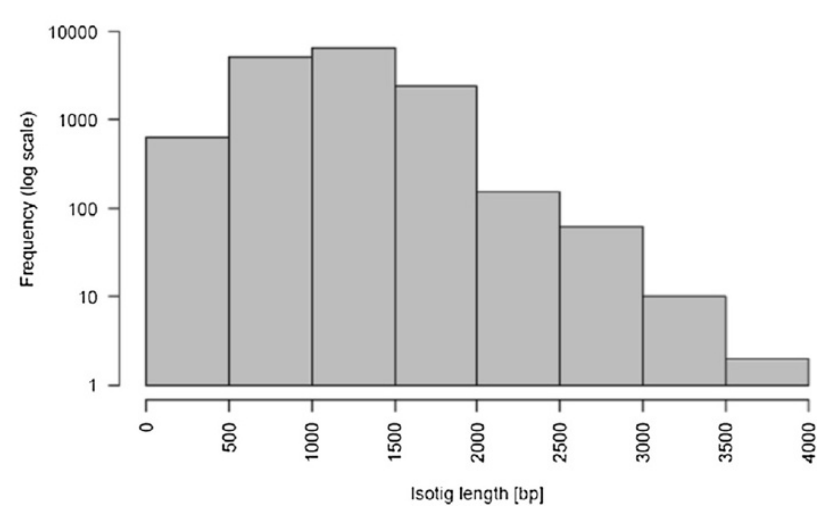

Figure 1 Overview of the sequencing and assembly of the $\boldsymbol{A}$. rusticana transcriptome. (A) Size distribution of the quality-filtered reads. Total number of reads: 556269, average/median length 342.9/379.0 (B) Length distribution of the 18511 contigs. Average/median length of the contigs: $717.7 / 667.0$ (C) Coverage distribution of the 18511 contigs. Average/median coverage of the contigs: 11.4/7.8 (D) Length distribution of the14871 isotigs. Average/median length of the isotigs: 1133.3/1113.0.

singletons. A detailed summary of the alignment and assembly process is described in Table 1.

\section{Plant peroxidase search and manual validation of assembled transcripts}

The position-specific scoring matrix (PSSM) corresponding to known horseradish peroxidases (cd00693) was used in a tblastn search in the assembled transcripts. The settings allowed for a very permissive filtering of putative peroxidases, thus including many false positives, but avoiding the loss of valuable data for further analyses. This search yielded hits in 91 transcripts, which were classified in secretory peroxidases, ascorbate peroxidases, glutathione peroxidases and peroxidase-like proteins by definition of the Conserved Domains Database (CDD, NCBI [33]). All previously known HRPs were classified as secretory peroxidases, so only the contigs comprising a secretory peroxidase conserved domain were kept. The horseradish transcriptome contigs of the 18 resulting secretory peroxidases were manually reviewed. In this process, the coding sequences of four contigs were extended with available assembly data, three contigs were split because of strongly conflicting reads, and two more contigs were discarded because of only a partial domain match that could not be resolved into a full-length sequence. In total, $20 \mathrm{HRP}$ genes, with allelic variants corresponding to 28 peroxidase isoenzymes, were identified in the transcriptome of $A$. rusticana. This includes isoenzymes $\mathrm{C} 1 \mathrm{~A}$ and $\mathrm{C} 3$ which could be partially retrieved from the raw reads although they did not form a fulllength contig. No read - even partially - corresponding to the previously published "neutral isoenzyme" N (Q42517) [11] was found.

\section{Sanger sequencing and genome walking}

Sequences yielded by the transcriptome assemblies are not necessarily error free but can include incorrect information either caused by the transcription and RNA editing machineries of the plant [34,35], introduced in the sequencing process or resulting from misassemblies. 
Table 1 Summary of the transcriptome sequencing, assembly and enzyme discovery results

\begin{tabular}{|c|c|c|}
\hline & $\begin{array}{l}\text { Number of } \\
\text { sequences }\end{array}$ & $\begin{array}{l}\% \text { of } \\
\text { total }\end{array}$ \\
\hline \multicolumn{3}{|l|}{ Transcriptome sequencing and assembly } \\
\hline Total number of reads & 592,507 & - \\
\hline Clipped reads & 556,269 & - \\
\hline Reads after Newbler quality control & 543,439 & 100.0 \\
\hline Reads aligned & 490,285 & 90.2 \\
\hline Reads assembled & 433,179 & 88.4 \\
\hline Reads partially assembled & 57,064 & 10.5 \\
\hline Singletons & 35,950 & 7.3 \\
\hline Contigs & 18,511 & - \\
\hline Isogroups & 10,619 & - \\
\hline Isotigs & 14,871 & - \\
\hline Average isotig length & 1,133 & - \\
\hline Largest isotig length & 3,659 & - \\
\hline Average contig coverage & 11.4 & - \\
\hline \multicolumn{3}{|l|}{ HRP isoenzyme discovery and verification } \\
\hline \# of isotigs with a secretory peroxidase domain & 18 & - \\
\hline \# of full length peroxidase genes & 18 & - \\
\hline \# of peroxidase genes after manual revision & 20 & - \\
\hline Total \# of isoenzymes (including allelic variants) & 28 & 100 \\
\hline Successfully verified from gDNA & 26 & 89.7 \\
\hline \multicolumn{3}{|l|}{ Enzyme production in Pichia pastoris } \\
\hline Synthetic genes for production & 26 & 89.7 \\
\hline Successful production of an active isoenzyme & 22 & 75.9 \\
\hline
\end{tabular}

The sequences of all peroxidase genes detected in the isotigs were verified on genome level by Sanger sequencing of amplified genomic DNA. In addition, the sequences of the isoenzymes $\mathrm{C} 1 \mathrm{~A}$ and $\mathrm{C} 3$ available in the databases and partially also found in the raw reads were revised. In case of five full-length contigs where no sufficient read data from untranslated regions was available to enable amplification and sequencing of the complete gene, a genome walking approach was successfully performed in order to verify the 5' and/or 3' regions of the respective gene. Divergent coding sequence information was observed for ten genes in the form of possible allelic variants. PCR artifacts were ruled out by repeated experiments to increase the coverage of the positions. Thus, conflicting sequence information was postulated not to be due to sequencing errors, but rather due to the high sequence similarity of the HRP isoenzymes and the permissive settings used in the assembly. Supporting this assumption, putative allelic sequences could be found as separate raw reads. For altogether nine positions in contigs 22684, 6117, 17517 and 23190 (Table 2) the nucleotide present in the transcriptome reads could not be found in the genomic DNA sequenced. The sequence of the previously published "neutral isoenzyme" N (Q42517) not present in the transcriptome sequences could not be amplified from genomic DNA (gDNA) either. Therefore, it was not included in the following analyses or experiments. The sequences of the transcript \# 22489 (see Table 2) could not be verified.

\section{GC content and codon usage}

The average GC content of all 14871 isotigs was calculated to be $42.7 \%$ (range $28 \%-62 \%$ ) (Figure 2), almost identical to the average GC content, $42.5 \%$, reported for A. thaliana [36]. This is lower than the average GC content of $45.1 \%$ reported by the Codon Usage Database (CUD) [37], suggesting that the small set of available $A$. rusticana genes (14 coding sequences) used in CUD for the calculation is not representative for the whole species. The GC content of the HRP isoenzymes was observed to vary between 42.9\% (C2, contig \#04627) and 51.0\% (contig \#22489), with an average GC content of $47.1 \%$. The results of the analysis are described in more detail in Table 3.

The codon usages of the HRP genes and the previously known $A$. thaliana peroxidases were compared in the form of heatmaps (Additional file 1), depicting the fold change of the codon usage frequencies compared to the expected (1/64) frequency ( $\triangle \mathrm{RSCU})$. The clustering of the isoenzymes according to their codon usage frequencies situated newly discovered isoenzymes with most divergent sequence and gene structure (HRP_3523, HRP_5508, HRP_22489, HRP_17517, HRP_23190) also furthest away from the previously known group $C$ isoenzymes.

\section{Gene structure and phylogenetic analyses}

Phylogenetic relationships of the HRP isoenzymes are shown in Figure 3 and Additional file 1. Interestingly, the previously known isoenzymes seem to be closely related to each other, while most of the new isoenzymes discovered in the transcriptome seem to share higher evolutionary distance to them. From the 20 peroxidase gene loci, 15 were confirmed to have three introns by comparing either transcript data or protein sequence data to the verified gDNA sequence. Further four genes $(5508,22489,17517$, 23190 ) were noted to have only two introns and one gene (3523) no introns (Table 3). The number of introns correlates with the evolutionary distance so that genes having aberrant intron numbers were situated in separate branches close to each other in the phylogenetic topology. With the information obtained from the reads, no alternative splicing could be shown. According to SignalP, all of the isoenzymes have an $\mathrm{N}$-terminal signal sequence varying in length from 18 amino acids to 31 amino acids. The lengths of the signal sequences are described in Table 3, and an alignment of the amino acid sequences of the HRP isoenzymes is shown in Additional file 2. 
Table 2 Comparison of the HRP isoenzyme sequences between GenBank, UniProt, transcriptome and verified genome sequences

\begin{tabular}{|c|c|c|c|c|c|c|c|}
\hline \multirow[t]{2}{*}{ HRP } & \multicolumn{2}{|c|}{ Sanger sequence } & \multicolumn{2}{|c|}{ Transcriptome sequence } & \multicolumn{2}{|c|}{ GenBank sequence } & \multirow{2}{*}{$\begin{array}{l}\text { UniProt sequence } \\
\qquad \text { aa }\end{array}$} \\
\hline & $\mathrm{Nt}$ & aa (exon)/intron & nt & aa & nt & aa (exon)/intron & \\
\hline \multirow[t]{3}{*}{ C1A } & TA & Y37 & - & - & AT & 137 & Y37 \\
\hline & 109-110 & & & & $109-110$ & & \\
\hline & C1159 & intron & - & intron & G1159 & intron & - \\
\hline \multirow[t]{2}{*}{$\mathrm{C} 1 \mathrm{~B}$} & $\mathrm{~T} / \mathrm{C} 253$ & intron & - & intron & T253 & intron & - \\
\hline & T/C859 & intron & - & intron & C859 & intron & - \\
\hline \multirow[t]{7}{*}{$\mathrm{C} 1 \mathrm{C}$} & ss & ss & ss & ss & * & * & * \\
\hline & $n t 1-60$ & aa1-20 & nt1-60 & aa1-20 & & & \\
\hline & C178 & R60 & $\mathrm{C} 178$ & R60 & A118 & $\$ 40$ & $\$ 40$ \\
\hline & A/T1335 & intron & - & intron & - & - & - \\
\hline & A/G1888 & T/A165 & A/G493 & T/A165 & G433 & A145 & A145 \\
\hline & C1889 & A165 & $\mathrm{C} / \mathrm{T} 1889$ & AN165 & & & \\
\hline & C/G1921 & Q/E176 & C/G526 & Q/E176 & G466 & E156 & E156 \\
\hline \multirow[t]{3}{*}{$\mathrm{C} 2$} & $\mathrm{CT}$ & intron & - & intron & * & intron & - \\
\hline & $1250-1251$ & & & & & & \\
\hline & A1334 & intron & - & intron & * & intron & - \\
\hline \multirow[t]{4}{*}{$\mathrm{C} 3$} & G/T1294 & intron & - & intron & G1294 & intron & - \\
\hline & A/T1323 & intron & - & intron & A1323 & intron & - \\
\hline & T/C1484 & L231 & - & - & T1484 & L231 & L231 \\
\hline & C/T1541 & $F 250$ & - & - & C1541 & $F 250$ & $F 250$ \\
\hline \multirow[t]{13}{*}{$\mathrm{A} 2$} & ss & sS & SS & ss & - & - & * \\
\hline & nt1-93 & aa1-31 & $1-93$ & aa1-31 & & & \\
\hline & AAT & N78 & AAT & N47 & - & - & D47 \\
\hline & $231-234$ & & $231-234$ & & & & \\
\hline & GGA & G220 & GGA & G220 & - & - & N189 \\
\hline & 996-998 & & $661-663$ & & & & \\
\hline & AAT & N221 & AAT & N221 & - & - & G190 \\
\hline & 999-1001 & & $664-666$ & & & & \\
\hline & ACG & T284 & ACG & T284 & - & - & L253 \\
\hline & 1185-1187 & & $850-852$ & & & & \\
\hline & G/A1203 & $\mathrm{A} / \mathrm{T} 290$ & G868 & A290 & - & - & A259 \\
\hline & AAT & N334 & AAT & N334 & - & - & D303 \\
\hline & 1335-1337 & & $999-1002$ & & & & \\
\hline \multirow[t]{5}{*}{ E5 } & sS & SS & SS & SS & - & - & * \\
\hline & nt1-81 & aa1-27 & nt1-81 & aa1-27 & & & \\
\hline & T419 & L82 & $\mathrm{C} / \mathrm{T} 246$ & L82 & - & - & L55 \\
\hline & C422 & D83 & T/C249 & D83 & - & - & D56 \\
\hline & C545 & C124 & T/C372 & $\mathrm{C} 124$ & - & - & C97 \\
\hline 01805 & None & none & none & none & - & - & - \\
\hline \multirow[t]{3}{*}{22684} & G1611 & R337 & A1010 & K337 & - & - & - \\
\hline & TGA & D343 & CGG & G343 & - & - & - \\
\hline & $1627-1629$ & & $1026-1028$ & & & & \\
\hline 01350 & None & none & none & none & - & - & - \\
\hline
\end{tabular}


Table 2 Comparison of the HRP isoenzyme sequences between GenBank, UniProt, transcriptome and verified genome sequences (Continued)

\begin{tabular}{|c|c|c|c|c|c|c|c|}
\hline \multirow[t]{2}{*}{ HRP } & \multicolumn{2}{|c|}{ Sanger sequence } & \multicolumn{2}{|c|}{ Transcriptome sequence } & \multicolumn{2}{|c|}{ GenBank sequence } & \multirow{2}{*}{$\begin{array}{c}\text { UniProt sequence } \\
\text { aa }\end{array}$} \\
\hline & $\mathrm{Nt}$ & aa (exon)/intron & nt & aa & nt & aa (exon)/intron & \\
\hline 02021 & None & none & none & none & - & - & - \\
\hline 03523 & None & none & none & none & - & - & - \\
\hline \multirow[t]{2}{*}{06117} & T30 & V10 & C/T30 & V10 & - & - & - \\
\hline & C1088 & 1269 & T807 & 1269 & - & - & - \\
\hline \multirow[t]{3}{*}{17517} & T190 & Y64 & C190 & $\mathrm{H} 64$ & - & - & - \\
\hline & C1157 & G282 & T846 & G282 & - & - & - \\
\hline & A1232 & K307 & G921 & K307 & - & - & - \\
\hline 08562.1 & None & none & none & none & - & - & - \\
\hline 08562.4 & None & none & none & none & - & - & - \\
\hline \multirow[t]{5}{*}{23190} & T1345 & S109 & G1345 & $S 109$ & - & - & - \\
\hline & C1423 & G135 & T1423 & G135 & - & - & - \\
\hline & T1842 & S222 & T/C1842 & S/P222 & & & \\
\hline & C1850 & T224 & A/C1850 & T224 & - & - & - \\
\hline & A 2221 & E348 & T/A2221 & V/E348 & - & - & - \\
\hline 04663 & None & none & none & none & - & - & - \\
\hline 06351 & None & none & none & none & - & - & - \\
\hline 05508 & G/A346 & $\mathrm{A} / \mathrm{T} 116$ & G/A346 & $\mathrm{A} / \mathrm{T} 116$ & - & - & - \\
\hline \multirow[t]{2}{*}{22489} & - & - & G/A597 & T199 & - & - & - \\
\hline & & & $\mathrm{G} / \mathrm{T} 715$ & A/S239 & - & - & - \\
\hline
\end{tabular}

All nucleotide (nt) and amino acid (aa) positions were calculated from the start ATG. Variations between the nt positions of the transcriptome sequence compared to other sequence sources are either due to deletions or intronic sequences in the other sources. "-" indicates that no sequence information is available from the respective source. "ss" indicates a putative signal sequence. Deletions or missing sequences are marked with "*". "N/NX" indicates a variation at position X. "None" indicates that no polymorphisms or differences between transcriptome and genome sequence were found. The isoenzymes C1 A and C3 were detected in the transcriptome raw reads with only partial/low coverage $(0-2 x)$, thus no consensus sequence was formed.

\section{Heterologous protein production in Pichia pastoris}

Twenty-six HRP sequences including allelic variants were codon optimized for P. pastoris expression and ordered as synthetic fragments. Twenty-two of them showed activity with at least one of the substrates tested, thus verifying a successful expression in $P$. pastoris. The peroxidase activities of the produced isoenzymes were detected with

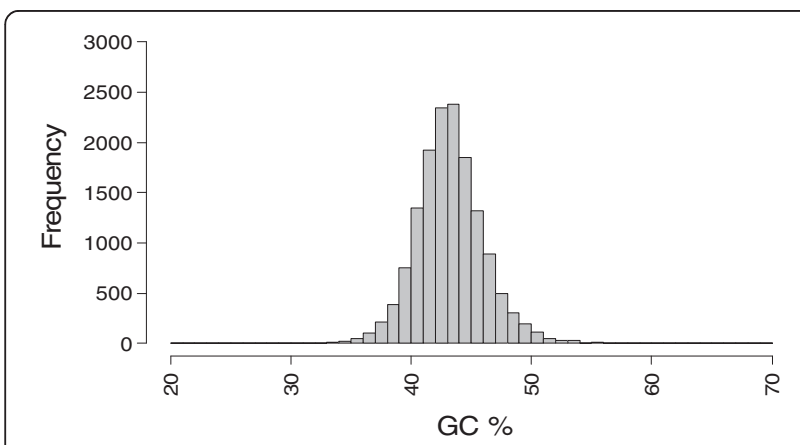

Figure $2 \mathrm{GC}$ content distribution of the $A$. rusticana isotigs. GC content distribution of the A. rusticana isotigs varies from $28 \%$ (min) to $62 \%$ (max) with a range of $35 \%$. The average GC content of all isotigs is $42.72 \%$. Mode (x-axis value) 43, mode value (y-axis value) 2376. four substrates having variable assay $\mathrm{pH}$ optima. The substrate or $\mathrm{pH}$-specific performance (Table 4) of the isoenzymes suggests a wide range of possible applications for this versatile group of peroxidases.

\section{Discussion}

Although high throughput sequencing technologies and bioinformatics tools to handle the enormous amount of data generated have been rapidly developing in the recent past, the expressed sequence data of many organisms of wide importance are still not available. Our study demonstrates how NGS technologies can provide a rapid, lowcost basis for the discovery of isoenzymes required for specific industrial, medical or biological applications. Below we discuss the reliability of the approach in identifying and characterizing an important group of isoenzymes, challenges provided by the library generation, sequencing and assembly methods, and suitability of the data obtained from the pipeline for heterologous protein production without laborious manual verification of the sequences.

A normalized cDNA collection originating from multiple $A$. rusticana tissues was sequenced with 454 pyrosequencing technology. In comparison to the other 
Table 3 Summary of the horseradish peroxidase isoenzymes and associated data produced during this study

\begin{tabular}{|c|c|c|c|c|c|c|c|c|c|}
\hline $\begin{array}{c}\text { Contig } \\
\text { number }\end{array}$ & $\begin{array}{c}\text { Name } \\
\left({ }^{*} \text { novel }\right)\end{array}$ & $\begin{array}{c}\text { Length } \\
\text { nt }\end{array}$ & $\begin{array}{c}\mathrm{GC} \\
\text { content } \% \\
\end{array}$ & $\begin{array}{c}\text { Accession } \\
\# \\
\end{array}$ & $\begin{array}{c}\text { CAl } \\
\text { calculated }\end{array}$ & $\begin{array}{c}\text { Intron } \\
\#\end{array}$ & $\begin{array}{c}\text { Signal sequence } \\
\text { length }\end{array}$ & $\begin{array}{l}\text { Disulfide bridges } \\
\text { (EDBCP prediction) }\end{array}$ & $\begin{array}{l}\text { pl mature } \\
\text { protein }\end{array}$ \\
\hline- & $\mathrm{C} 1 \mathrm{~A}$ & 1062 & 43.69 & HE963800 & 0.812 & 3 & 30 & [11-91] [44-49] [97-301] [177-209] & 5.59 \\
\hline 15901 & $\mathrm{C} 1 \mathrm{~B}$ & 1056 & 43.94 & HE963801 & 0.808 & 3 & 28 & [11-91] [44-49] [97-301] [177-209] & 5.84 \\
\hline 25148 & $\mathrm{C} 1 \mathrm{C}^{*}$ & 1059 & 45.14 & HE963802 & 0.809 & 3 & 29 & [11-91] [44-49] [97-301] [177-209] & 6.49 \\
\hline 25148_2 & $C 1 D^{*}$ & 1059 & 45.04 & HE963803 & 0.810 & 3 & 29 & [11-91] [44-49] [97-301] [177-209] & 7.04 \\
\hline 04627 & $\mathrm{C} 2$ & 1044 & 42.91 & HE963804 & 0.800 & 3 & 24 & [11-91] [44-49] [97-301] [177-209] & 8.56 \\
\hline- & C3 & 1050 & 46.76 & HE963805 & 0.781 & 3 & 29 & [11-91] [44-49] [97-300] [177-209] & 7.71 \\
\hline $\begin{array}{l}\text { Manual } \\
\text { assembly }\end{array}$ & $\mathrm{A} 2 \mathrm{~A}^{*}$ & 1011 & 46.79 & HE963806 & 0.761 & 3 & 31 & [11-91] [44-49] [97-299] [176-208] & 4.93 \\
\hline $\begin{array}{l}\text { Manual } \\
\text { assembly }\end{array}$ & $A 2 B^{*}$ & 1011 & 46.69 & HE963807 & 0.761 & 3 & 31 & [11-91] [44-49] [97-299] [176-208] & 4.93 \\
\hline 04382 & E5 & 1044 & 46.07 & HE963808 & 0.771 & 3 & 27 & [11-91] [44-49] [97-300] [177-209] & 8.84 \\
\hline 01805 & $1805^{*}$ & 1065 & 44.41 & HE963809 & 0.797 & 3 & 31 & [11-91] [44-49] [97-301] [177-209] & 5.97 \\
\hline 22684 & $22684.1^{*}$ & 1050 & 46.76 & HE963810 & 0.770 & 3 & 29 & [11-91] [44-49] [97-300] [177-209] & 6.98 \\
\hline 22684_2 & $22684.2^{*}$ & 1050 & 46.67 & HE963811 & 0.772 & 3 & 29 & [11-91] [44-49] [97-300] [177-209] & 6.37 \\
\hline 01350 & $1350^{*}$ & 975 & 50.97 & HE963812 & 0.707 & 3 & 28 & [11-91] [44-49] [97-292] [176-201] & 8.67 \\
\hline 02021 & $2021^{*}$ & 996 & 46.08 & HE963813 & 0.788 & 3 & 29 & [11-89] [44-49] [95-297] & 9.46 \\
\hline 23190 & $23190.1^{*}$ & 1080 & 49.26 & HE963817 & 0.724 & 2 & $\begin{array}{l}31 \\
42\end{array}$ & $\begin{array}{l}\text { [11-92] [44-49] [98-293] [178-205] or } \\
{[22-103][55-60][109-304][189-216]}\end{array}$ & $\begin{array}{l}8.40 \\
6.58\end{array}$ \\
\hline 23190_2 & $23190.2^{*}$ & 1080 & 49.17 & HE963817 & 0.722 & 2 & $\begin{array}{l}31 \\
42\end{array}$ & $\begin{array}{l}{[11-92][44-49][98-293][178-205] \text { or }} \\
{[22-103][55-60][109-304][189-216]}\end{array}$ & $\begin{array}{l}8.60 \\
7.09\end{array}$ \\
\hline 04663 & $4663^{*}$ & 1077 & 47.82 & HE963814 & 0.748 & 3 & 31 & [11-91] [44-49] [97-299] [176-208] & 4.48 \\
\hline 06351 & $6351^{*}$ & 945 & 43.39 & HE963816 & 0.786 & 3 & 18 & [17-96] [50-55] [102-292] [180-206] & 6.37 \\
\hline 03523 & $3523^{*}$ & 960 & 44.58 & HE963820 & 0.761 & 0 & 22 & [11-92] [44-49] [98-293] [177-203] & 8.99 \\
\hline 05508 & $5508.1^{*}$ & 966 & 49.28 & HE963815 & 0.735 & 2 & $\begin{array}{l}24 \\
30\end{array}$ & $\begin{array}{c}{[11-87][44-49][93-287][171-198] \text { or }} \\
\text { [17-93] [50-55] [99-293] [177-204] }\end{array}$ & $\begin{array}{l}8.49 \\
8.47\end{array}$ \\
\hline 05508_2 & $5508.2^{*}$ & 966 & 49.38 & HE963815 & 0.735 & 2 & $\begin{array}{l}24 \\
30\end{array}$ & $\begin{array}{c}{[11-87][44-49][93-287][171-198] \text { or }} \\
{[17-93][50-55][99-293][177-204]}\end{array}$ & $\begin{array}{l}8.49 \\
8.47\end{array}$ \\
\hline 22489_1 & $22489.1^{*}$ & 978 & 51.02 & HE963818 & 0.726 & 2 & $\begin{array}{l}23 \\
34\end{array}$ & $\begin{array}{c}{[22-98][55-60][104-298][182-209] \text { or }} \\
\text { [11-87] [44-49] [93-287] [171-198] }\end{array}$ & $\begin{array}{l}8.93 \\
8.51\end{array}$ \\
\hline 22489_2 & $22489.2^{*}$ & 978 & 50.82 & HE963819 & 0.727 & 2 & $\begin{array}{l}23 \\
34\end{array}$ & $\begin{array}{c}{[22-98][55-60][104-298][182-209] \text { or }} \\
\text { [11-87] [44-49] [93-287] [171-198] }\end{array}$ & $\begin{array}{l}8.93 \\
8.51\end{array}$ \\
\hline 06117 & $6117^{*}$ & 1008 & 47.02 & HE963821 & 0.802 & 3 & $\begin{array}{l}22 \\
32\end{array}$ & $\begin{array}{l}{[11-91][44-49][97-298][176-208] \text { or }} \\
{[21-101][54-59][107-308][186-218]}\end{array}$ & $\begin{array}{l}5.52 \\
6.16\end{array}$ \\
\hline 17517_1 & $17517.1^{*}$ & 972 & 48.46 & HE963822 & 0.737 & 2 & $\begin{array}{l}23 \\
24\end{array}$ & $\begin{array}{c}\text { [12-88] [45-50] [94-296] [171-203] or } \\
{[11-87][44-49][93-295][170-202]}\end{array}$ & $\begin{array}{l}9.49 \\
9.39\end{array}$ \\
\hline 17517_2 & $17517.2^{*}$ & 972 & 48.56 & HE963823 & 0.739 & 2 & $\begin{array}{l}23 \\
24\end{array}$ & $\begin{array}{c}\text { [12-88] [45-50] [94-296] [171-203] or } \\
\text { [11-87] [44-49] [93-295] [170-202] }\end{array}$ & $\begin{array}{l}9.52 \\
9.41\end{array}$ \\
\hline 08562_1 & $08562.1^{*}$ & 996 & 47.09 & HE963824 & 0.779 & 3 & $\begin{array}{l}22 \\
28\end{array}$ & $\begin{array}{c}{[11-91][44-49][97-298][176-208] \text { or }} \\
{[17-97][50-55][103-304][182-214]}\end{array}$ & $\begin{array}{l}9.01 \\
9.03\end{array}$ \\
\hline 08562_4 & $08562.2^{*}$ & 996 & 47.79 & HE963825 & 0.788 & 3 & $\begin{array}{l}22 \\
28\end{array}$ & $\begin{array}{c}{[11-91][44-49][97-298][176-208] \text { or }} \\
{[17-97][50-55][103-304][182-214]}\end{array}$ & $\begin{array}{l}9.00 \\
9.02\end{array}$ \\
\hline
\end{tabular}

The nucleotide sequences of 28 isoenzymes were submitted to EMBL. "*" indicates novel. "CAl" = codon adaptation index. If signal sequence predictions gave more than one alternative result, both signal sequence lengths are shown, separated by "/". Disulfide bridges were predicted using both alternatives of the mature protein $(E D B C P=$ Ensemble-based Disulfide Bonding Connectivity Pattern prediction server).

NGS methods, 454 pyrosequencing produces long reads. This is of advantage when sequencing genes coding for isoenzymes and identifying exonic variants. Longer reads increase the probability to uniquely align a given read, which might be problematic with the short reads produced by other NGS methods [38]. Studies in $A$. thaliana suggested that with the high coverage attainable by massively parallel sequencing, all transcripts can be well represented in the sequence data regardless of expression levels [17]. However, the benefits of normalization in 


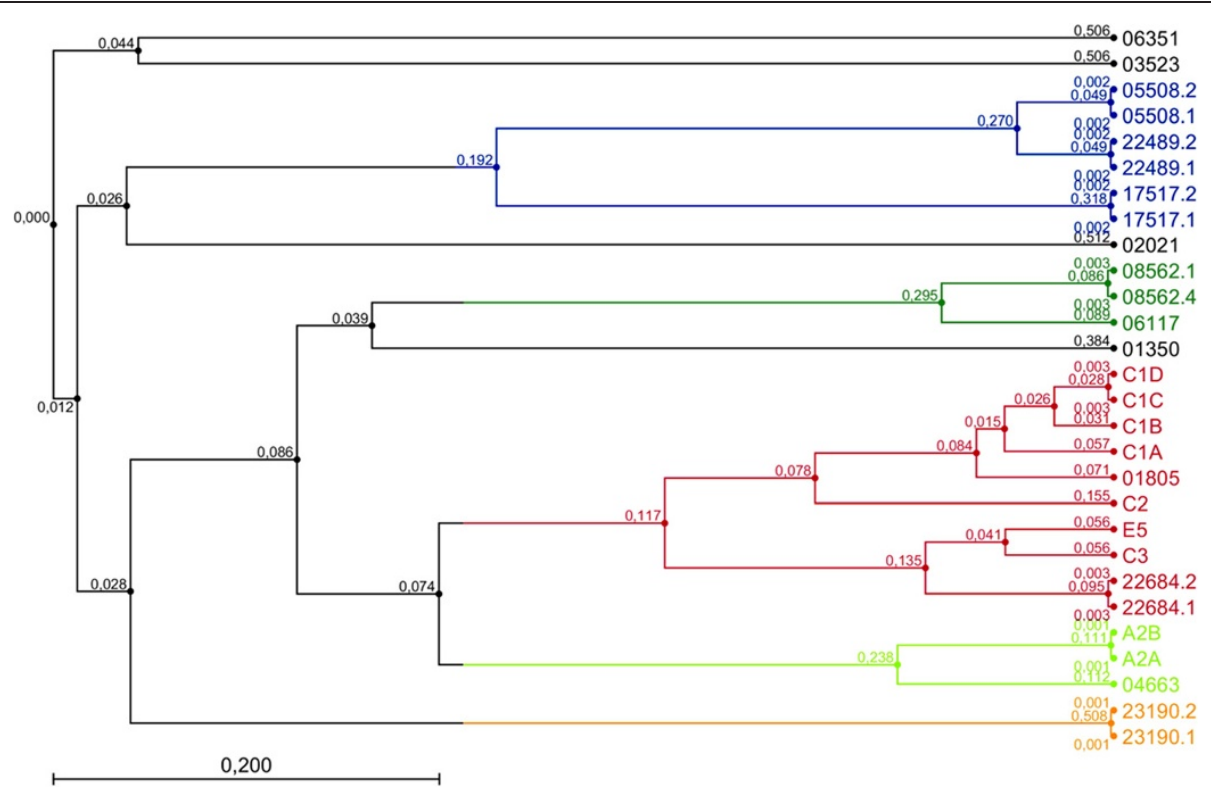

Figure 3 Cladogram of all isoenzymes known and discovered during this study. The dendrogram was cut at a branch length of 0.21 and the resulting sub-trees were colored. All previously described isoenzymes are located in the red and light green trees, respectively; whereas all novel isoenzymes (except for 01805, 22684.1, 22684.2, and 04663) cluster in distinct sub-trees (black, blue, dark green and orange) indicating a larger sequence diversity.

non-model species have not been well characterized, and a recent study by Cirulli et al. reports low identification rates of exonic SNVs (single nucleotide variations) in non-normalized transcriptome, if the genes of interest are not well-expressed in the source tissue [38]. Since also the genome and transcriptome sizes of $A$. rusticana and the sequence data required to reach also isoenzymes with low expression levels are unknown, the cDNA library sequenced in this study was normalized. Normalization of the cDNA has been reported to be especially important in gene discovery when the cDNA used for sequencing is pooled from many tissues or individuals [39-41], and to considerably reduce the frequency of abundant transcripts thus increasing the possibility to reach also unique transcripts of isoenzymes with low expression levels. Half a plate run on a GS FLX platform resulted in over 500000 high-quality reads, corresponding to a relatively high average coverage $(>10 x)$ of the assembled 14871 isotigs with a high average length of $1133 \mathrm{bp}$. Comparable to previous transcriptome sequencing studies $[40,41], 88 \%$ of the reads could be assembled into contigs. Many of the remaining singletons were of high quality and also represented an important source of information [18]. Singletons could either result from 454 sequencing errors or contaminants from plant parasites [42], they could be caused by over-efficient normalization methods, or simply represent rare transcripts with thin coverage despite the normalized cDNA pool used for sequencing.
The 454 pyrosequencing technique generates relatively long reads including very few technical errors (mainly related to homopolymer runs), and is therefore well-suited for applications such as de novo transcriptome sequencing. Although the sequence length achieved by 454 Titanium FLX platform is still clearly shorter than by traditional Sanger sequencing, it has been reported to be adequate for reconstructing full length transcripts [17] and validated to be comparable in accuracy to Sanger sequencing [43,44]. The high average isotig length of $1133 \mathrm{bp}$ and the assembly of $90 \%(18 / 20)$ full length peroxidase genes reached in this study supports the statement of adequate read length and coverage to detect complete transcripts. Only isoenzymes $\mathrm{C} 1 \mathrm{~A}$ and $\mathrm{C} 3$ were not assembled into a contig due to low sequence coverage.

Although the error rates associated with NGS methods have been reported to be low, they could still cause problems in reliable sequence polymorphism detection. The requirement of $>90 \%$ match used in this study, combined with a minimal match length of 40 bp was expected to provide a very high number of contigs without collapsing and joining similar isoenzymes into a single contig [18]. However, the isoenzyme sequences were known to be partially almost identical. To validate the assembly and ORF (open reading frame) prediction correctness, and the existence of allelic variants, the isoenzyme sequences were amplified from genomic DNA. The combination of transcriptome sequencing and Sanger sequencing of amplified genomic DNA revealed 38 variable positions in the coding sequences of 11 genes. For 
Table 4 Summary of isoenzyme expression and characterization

\begin{tabular}{|c|c|c|c|c|c|}
\hline Contig number & Name (* previously unknown) & Activity ABTS & Activity TMB & Activity guaiacol & Activity pyrogallol \\
\hline- & C1A & + & + & + & + \\
\hline 15901 & $\mathrm{C} 1 \mathrm{~B}$ & - & + & - & - \\
\hline 25148 & $\mathrm{C} 1 \mathrm{C}^{*}$ & + & + & $(+)$ & + \\
\hline 25148_2 & $C 1 D^{*}$ & + & + & $(+)$ & + \\
\hline 04627 & C2 & + & + & + & + \\
\hline- & C3 & + & + & + & + \\
\hline Manual assembly & $A 2 A^{*}$ & + & + & + & + \\
\hline Manual assembly & $A 2 B^{*}$ & + & + & $(+)$ & $(+)$ \\
\hline 04382 & E5 & + & + & + & + \\
\hline 01805 & $01805^{*}(\mathrm{~B} 1 ?)$ & + & + & - & - \\
\hline 22684 & $22684.1^{*}(B 2 A ?)$ & + & + & - & - \\
\hline 22684_2 & 22684.2* (B2B?) & + & + & - & - \\
\hline 01350 & $01350^{*}$ & + & + & - & - \\
\hline 02021 & $02021^{*}$ & - & - & - & - \\
\hline 23190 & $23190.1^{*}$ & - & - & - & - \\
\hline 23190_2 & $23190.2^{*}$ & n.d. & n.d. & n.d. & n.d. \\
\hline 04663 & $04663.1^{*}$ & + & $(+)$ & - & - \\
\hline 06351 & $06351^{*}$ & + & + & + & + \\
\hline 03523 & 03523* & - & - & - & - \\
\hline 05508 & $05508.1^{*}$ & + & + & + & + \\
\hline 05508_2 & $05508.2^{*}$ & n.d. & n.d. & n.d. & n.d. \\
\hline 22489_1 & $22489.1^{*}$ & + & + & $(+)$ & + \\
\hline 22489_2 & $22489.2^{*}$ & + & + & $(+)$ & + \\
\hline 06117 & $06117^{*}$ & - & - & - & - \\
\hline 17517_1 & $17517.1^{*}$ & + & - & - & - \\
\hline 17517_2 & $17517.2^{*}$ & + & + & + & + \\
\hline 08562_1 & $08562.1^{*}$ & + & + & - & - \\
\hline 08562_4 & $08562.2^{*}$ & + & + & - & + \\
\hline
\end{tabular}

Isoenzymes showing obvious peroxidase activity with the assay used are marked with " + ". Isoenzymes showing very low but detectable peroxidase activity with the assay used are marked with " $(+)$ ". Isoenzymes with no activity detected during an observation period of $2 \mathrm{~h}$ are marked with "-“. Allelic variants not produced heterologously are marked with n.d. (no data available). Isoenzymes discovered during this study are marked with "**".

nine positions thereof (in four transcripts) the corresponding nucleotide could not be found in the genomic DNA. Manual confirmation of the transcriptome reads revealed that the coverage of all positions was high and that the reads agreed. Closer analysis of the positions also ruled out false variations caused by too high coverage. At relatively low or moderate levels of coverage, sequencing mistakes are not pushed over. Too high sequencing depth increases noise and could have introduced, without very strict quality control, false variations [38]. Therefore, sequencing errors could be excluded as the source of the differences. The differences could be caused either by mismatches introduced by the reverse transcriptase enzyme during library generation, as a result of RNA editing events $[34,35]$ or reflect the natural variation between individual plants and plant parts. The general error rate of the sequencing technique was noted to be very low, but isoenzymes coded by less common allelic variants would have been missed without manual sequence verification. Twenty-six of the resulting coding sequences, including allelic variants missed in the transcriptome sequencing and assembly processes, were codon optimized, synthesized and transformed to $P$. pastoris for expression.

This study reveals that for the coverage of all isoenzymes including allelic variants represented by the cDNA library sequenced, manual work to verify the resulting transcript sequences cannot be avoided. However, the allelic variants represent only a minor part of the newly discovered enzymes. The quality of the sequences is very high and differences to genomic DNA minimal, confirming that the enzyme discovery method described in this 
study for high-throughput applications would not necessarily require manual verification of the sequencing by laborious Sanger sequencing of amplified genomic DNA. However, manual curation of the contigs of interest and splitting of the data in contigs with clear assembly conflicts can be done and could be worthwhile, as especially the additive effects of amino acid changes in collapsed contigs could cause problematic changes in the enzyme structure. The primary enzyme discovery pipeline utilized in this study provides a functional approach to find proteins of interest for heterologous production, giving an example of an affordable standardized sequencing project. Despite the large amount of useful data produced by the NGS approach, our study showed that sequence confirmation and data validation should not be neglected.

For the heterologous secretory production of single isoenzymes in $P$. pastoris, the codon usages of the coding sequences were optimized for efficient translation, and fragments corresponding to the predicted mature isoenzymes were produced synthetically. When the signal peptide prediction with SignalP led to two alternative signal peptide junctions, the mature peptides corresponding to the longer signal peptide variants were ordered as synthetic fragments, and the signal peptide variants with shorter mature peptide were successfully amplified via PCR. Correct cloning of all genes into P. pastoris expression vectors was verified by Sanger sequencing. Since the used $P$. pastoris expression vector already contains the signal sequence of the $S$. cerevisiae mating factor $\alpha$, the isoenzymes were produced without the predicted natural signal sequences. Twenty-two isoenzymes showed peroxidase activity with at least one of the substrates used. All activities were measured with four different assays over a $\mathrm{pH}$ range from 4.5 to 7 . Interestingly, for each assay (Table 4) a different isoenzyme showed the highest activity thus suggesting variable substrate specificities or $\mathrm{pH}$ optima. This observation further emphasizes the importance of the availability of a large group of individually produced pure isoenzymes to be able to comprehensively respond to the need of variable performance parameters including substrate specificity, activity, stability, and operating $\mathrm{pH}$ optimum. Four of the isoenzymes did not show peroxidase activity with the assays used. This could either be due to very low yields of active enzyme, totally inactive enzyme or unsuitable assay conditions.

The isoenzyme $\mathrm{C} 1 \mathrm{~A}$ was reported to be the most abundant isoenzyme in A. rusticana [1] and was thus expected to be found in the transcriptome. However, only two raw reads covering a minor part of the coding sequence could be detected. This might either suggest over-normalization of the cDNA library decreasing the total counts of the putatively most abundant transcripts to almost zero [45], or happen due to naturally occurring genetic variation with phenotypic correlation to adaptations to natural environments ranging from pathogens, light conditions or abiotic stress to a variety of other environmental perturbations $[8,46,47]$. Although mRNA originating from all available plant parts was used to reach genes activated at diverse stages of $A$. rusticana growth, some developmental stages were not present and the absence of certain isoenzymes due to missing tissues cannot be ruled out. This finding might illustrate the high variance of $H R P$ expression in A. rusticana plants and consequently the variance in the commercial HRP preparations, thus underlining the clear need for a reliable heterologous expression system that enables a consistent isoenzyme quality.

Peroxidase isoenzymes have been suggested to have multiple roles in the plant and thus also be variedly expressed depending on both biotic and abiotic factors [8]. To roughly estimate the expression levels of the newly discovered peroxidase genes, their GC contents and codon usages were assessed. Genes that are highly expressed have been suggested to possess a higher GC content and a more biased codon usage than genes with low expression levels [48]. A majority of both eukaryotic and prokaryotic species with large population sizes have been reported to have non-random codon usage mainly due to Darwinian selection between synonymous codons [49-51]. Highly expressed genes have been reported to use a restricted set of codons to ensure optimal translational efficiency [52,53]. In addition to gene expression levels, $\mathrm{GC}$ content has also been connected to gene regulation [54-57] and correlated with genomic features including methylation pattern [58], short intron length [59] and gene density [60] thus suggesting possible functional relevance. The codon usages and GC contents calculated using the verified coding sequences of the isoenzymes are described in Table 3. As expected, large variation between isoenzymes exist. These findings could suggest a spatial and temporal distribution of the isoenzymes in cellular processes [61].

Phylogenetic relationships of the HRP isoenzymes are shown in Figure 3. Whereas the previously known isoenzymes are closely related to each other, most of the new isoenzymes discovered in the transcriptome share higher evolutionary distance to the previously known HRPs. BLASTX analysis to the peroxidases of A. thaliana (Additional file 3) revealed that the A. rusticana peroxidases share $81 \%$ to $95 \%$ sequence similarity to the most similar isoenzyme of $A$. thaliana. Evolutionary distance does not necessarily correlate with altered substrate specificity, specific activity or optimal reaction conditions, but the discovery of new evolutionary branches with higher structural diversity does offer optimal conditions for the generation of an 
enzyme assortment with diverse properties for a wide variety of biomedical and industrial applications.

A combination of cDNA sequencing and gDNA verification in this study also provided valuable information of the intron-exon boundaries of the HRP genes. The number of exons in the isoenzymes was noted to vary from one to four, corresponding to zero to three introns. A large majority ( $75 \%$ of the peroxidase loci) of the isoenzymes were found to have four exons and three introns. Intron numbers have been reported to be highly conserved, but total intron length (total sum of the sizes of all introns within a gene) rather correlated to the GC-content of the gene [62]. Thus, intron number could be informative in terms of evolutionary origin and distance of the enzyme. In this study, intron numbers were found to correlate with the phylogenetic relationships of the amino acid sequences. Contigs with an unusual number of introns (none or two, Table 3) were situated in close proximity to each other furthest away from the previously known isoenzymes and clustered together when comparing the codon usage frequencies. With the information obtained from the reads, no alternative splicing could be observed.

The well-characterized isoenzyme HRP C1A has been reported to have a signal peptide consisting of 30 amino acids, and a carboxy-terminal extension suggested to target the protein to the vacuoles [63]. Also other known isoenzymes of the group $\mathrm{C}(\mathrm{C} 1 \mathrm{~B}, \mathrm{C} 1 \mathrm{C}, \mathrm{C} 2$, and $\mathrm{C} 3)$ have been reported to have signal peptides varying in length from 9 amino acids (C1C) to 29 amino acids (C3). By observing the alignment of all previously known and newly discovered isoenzymes (Additional file 2), existence of signal sequences also in other previously known and most of the new isoenzymes seemed very probable. According to the signal sequence prediction (SignalP) performed, all isoenzymes seem to have a signal sequence varying in length from 18 to 31 amino acids (Table 3, Additional file 2). Isoenzyme $\mathrm{C} 1 \mathrm{C}$, previously reported to have a signal sequence of nine amino acids, was predicted to have - better corresponding to the sequences of the very closely related isoenzymes $\mathrm{C} 1 \mathrm{~A}$ and $\mathrm{C} 1 \mathrm{~B}$ - a signal sequence of 29 amino acids. In the case of unclear signal sequence prediction with more than one option for the length of the signal peptide, both forms were taken into consideration when planning the constructs for enzyme production in $P$. pastoris.

\section{Conclusions}

To facilitate the possibilities for heterologous expression and isoenzyme characterization, we have elucidated the nucleotide sequences of 28 horseradish peroxidase isoenzymes by using the data obtained from $A$. rusticana 454 transcriptome sequence analysis with manual verification of PCR amplified genomic DNA. Although studies including transcriptome analysis of non-model species have become increasingly popular since the emergence of the NGS technologies, methods for the utilization of the 454 technology for the purpose of isoenzyme discovery in non-model plant species have not been established. In this project, transcriptome sequencing reads are further processed with alternative assemblies and manual sequence verification to determine the nucleotide sequences of all HRP isoenzymes. This study does not only contribute a set of transcripts, which can be used for marker development and genomic studies to understand agriculturally important traits in A. rusticana, but also provides valuable information of the peroxidase gene structure. Twenty-two of the verified isoenzymes have been produced in a form that was found active towards the tested substrates in $P$. pastoris utilizing a new $P$. pastoris expression platform [64], validating the success of the approach and providing first insights into the versatility of this large group of isoenzymes discovered.

\section{Methods}

\section{Plant specimens, RNA extraction and quality analysis}

Wild horseradish (A. rusticana) roots were purchased from local farmers and grown in the laboratory to obtain fresh roots, sprouts, stems and leaves. Tissues were collected in aliquots, frozen in liquid nitrogen and stored at $-80^{\circ} \mathrm{C}$. Total RNA from all available plant parts was isolated using RNaqueous kit (Applied Biosystems/Ambion, Austin, TX, USA) according to the manufacturer's recommendations. Quality assessment to ensure RNA integrity was performed with Agilent 2100 Bioanalyzer (Agilent Technologies, Santa Clara, CA, USA).

\section{Normalized cDNA library construction and sequencing}

Transcriptome sequence was obtained by a commercial service from LGC Genomics (Berlin, Germany). The methods used are roughly summarized as follows: mRNA was purified from total RNA using mRNA-ONLY ${ }^{\mathrm{m}}$ Eukaryotic mRNA Isolation Kit (Epicentre, Madison, WI, USA). One $\mu \mathrm{g}$ of mRNA was used for first-strand cDNA synthesis and amplification according to the MintUniversal cDNA Synthesis Kit user manual (Evrogen, Moscow, Russia), followed by a normalization reaction using the Trimmer Kit (Evrogen). Normalized material was re-amplified, digested (SfiI), size-selected ( $>800 \mathrm{bp}$, LMP agarose), purified (Qiagen, Hilden, Germany) and ligated to pDNR-lib vector (Clontech, Saint-Germain-en-Laye, France) using the Fast Ligation Kit (New England Biolabs, Ipswich, MA, USA). The desalted ligation was used to transform NEB10b competent cells (New England Biolabs).

Roughly a million clones were plated on LB (lysogeny broth + chloramphenicol $(\mathrm{Cm})$ plates, scraped off the plates and stored as glycerol stocks at $-70^{\circ} \mathrm{C}$. Plasmid DNA was prepared using standard methods (Qiagen, 
Hilden, Germany), and digested with SfiI. cDNA inserts were gel-purified (LMP-Agarose/MinElute Gel Extraction Kit, Qiagen) and ligated to high-molecular-weight DNA using a proprietary SfiI-linker.

Library generation for the 454 FLX sequencing was carried out according to standard protocols (Roche/454 Life Sciences, Branford, CT 06405, USA). In short, the concatenated inserts were sheared randomly by nebulization to fragments ranging in size from $400 \mathrm{bp}$ to $900 \mathrm{bp}$. These fragments were end polished and the 454 A and B adaptors that are required for the emulsion PCR and sequencing were ligated to the ends of the fragments. The resulting fragment library was sequenced on half a picotiterplate on the GS FLX using the Roche/ 454 Titanium chemistry. Sequence data can be accessed via the EMBL-EBI European Nucleotide Archive under the study accession number PRJEB5793.

\section{Assembly of the sequence reads to transcripts}

Raw reads produced by the pyrosequencing process were screened for the SfiI-linker that was used for concatenation and the linker sequences were clipped from the reads. Poly A/T sequences were mostly ( $90 \%)$ removed with the linker. High-quality reads were selected using Newbler sequence filtering at default settings. The clipped, quality controlled reads were assembled into individual isotigs using the Roche/454 Newbler software (454 Life Sciences Corporation, version 2.5.3) with default settings (minimum read length 20, duplicate reads excluded, expected depth 0 , seed step 12 , seed length 16 , seed count 1, minimum overlap length $40 \mathrm{bp}$, minimum overlap identity $90 \%$, alignment identity score 2 , alignment difference score -3 ).

\section{Discovery of peroxidases in the assembled contigs}

The PSSM (position-specific scoring matrix) corresponding to known horseradish peroxidases was obtained from NCBI's Conserved Domain Database (cd00693, CDD v3.01) [65]. It was used in a tblastn search (e-value cutoff 1e-5) [66] on the assembled contigs to yield a preliminary set of HRP candidate sequences. This set was refined by filtering sequences whose translation mapped back to a domain different to the original profile PSSM in an rpsblast classification of the entire CDD or had a bit score lower than the NCBI-specified threshold for a specific domain match. The read composition of the refined set of contigs was manually reviewed using SeqMan (DNASTAR, Madison, Wisconsin, USA). Isotigs where two apparently different variants were assembled into one contig by the assembler were split. Protein coding regions were extended using read information if two or more reads contained the same sequence.

\section{Genome walking and manual verification of horseradish peroxidase sequences}

The sequences of the identified peroxidase genes were manually verified by Sanger sequencing of PCR amplified genomic fragments using Phusion ${ }^{\text {TM }}$ High-Fidelity Polymerase (Finnzymes Oy, Espoo, Finland) and primers listed in Additional file 4. If no flanking regions were available for primer design, genome walking [67] was utilized to clarify and complete the sequences of the $\mathrm{C}-$ and N-termini. Therefore, $2 \mu \mathrm{g}$ aliquots of genomic DNA were singly digested with Bsp143I, HindIII, PsuI (Fermentas, St. Leon-Rot, Germany), BsaWI (New England Biolabs GmbH, Frankfurt am Main, Germany) or XhoII (Promega GmbH, Madison, WI, USA) in order to get fragments of $1-5 \mathrm{~kb}$ size. The digestion was stopped by heat inactivation of the enzymes, the fragmented DNA was precipitated with ethanol and the pellet was dissolved in $30 \mu \mathrm{L}$ of distilled water. An adaptor was created by annealing adaptor strand 1 (5'-GTAA TACGACTCACTATAGGGCACGCGTGGTCGACGGCC CGGGCTGGT-3') either to adaptor strand 2.a (3'-TCCC CGACCACTAG-5') for Bsp143I/PsuI-/XhoII-digested DNA, 2.b (3'-TCCCCGACCATTAA-5') for BsaWI-digested DNA or 2.c (3'-TCCCCGACCATCGA-5') for HindIII- digested DNA.

In the annealing reaction, adaptor strand 1 was mixed in 1:1 molar ratio with adaptor strand 2.a/2.b/2.c (i.e. $13.7 \mu \mathrm{L}$ of $100-\mu \mathrm{M}$ adaptor strand $1+4.0 \mu \mathrm{L}$ of $100 \mu \mathrm{M}$ adaptor strand 2) and heated to $95^{\circ} \mathrm{C}$ for $5 \mathrm{~min}$. To anneal the two strands to a functional adaptor molecule, the mixture was allowed to slowly cool down to room temperature. The three differently annealed adaptors $(1+2 \mathrm{a}, 1+2 \mathrm{~b}, 1+2 \mathrm{c})$ were ligated for three hours at room temperature with T4 DNA Ligase (Fermentas) to the digested DNA fragments, considering the specific 5 ' overhangs that have been created by the respective restriction enzymes. The ligation reaction was stopped by incubation for $5 \mathrm{~min}$ at $70^{\circ} \mathrm{C}$ and $70 \mu \mathrm{L}$ of TE (Tris-EDTA) buffer was added. Two gene-specific primers and two adaptor primers were designed. The gene-specific primers were designed to bind approximately $100 \mathrm{bp}$ from the end of the known sequence, considering that no restriction site of the restriction enzymes used for DNA digestion laid between the primer-binding site and the end of the known sequence. AdaptorPrimer1 (5'-GTAATACGACTCACTATAGGGC-3') and GeneSpecificPrimer1 were used as a primer pair for a first PCR with $1 \mu \mathrm{L}$ of the DNA + adaptor ligation product as template DNA. One $\mu \mathrm{L}$ of the first PCR mix was used as template for a second PCR with AdaptorPrimer2 (5'-ACTATAGGGCACGCGTGGT-3') and GeneSpecificPrimer2. This second primer pair was designed to bind within the first PCR product. Both PCR steps were performed with an elongation time of 50 seconds. 
A gene-specific DNA fragment as product from the second PCR was isolated from a preparative agarose gel, purified (SV DNA extraction kit, Promega) and sent to Sanger sequencing (LGC Genomics GmbH, Berlin, Germany), using AdaptorPrimer2 and the corresponding GeneSpecificPrimer2. If unspecific primer binding or nucleotide polymorphisms were suspected, the PCR products were cloned into the pJET 1.2blunt vector (GeneJet cloning kit, Promega), transformed to $E$. coli Top10 $\mathrm{F}^{\prime}$ and plasmids from single colonies were isolated for sequencing to ensure the read consisted of only one allele.

The resulting gene sequences were submitted to EMBL [68] under accession numbers HE963800-HE963825 (Table 3).

\section{Codon usage, GC content, isoelectric point, signal sequence prediction, disulfide bridge prediction and phylogenetic analyses of the horseradish peroxidase isoenzymes}

Codon usages and GC contents of the HRP isoenzymes were analyzed using CAIcal [69,70] and Mega5 [71,72]. The sequences of the $A$. thaliana Class III peroxidases were downloaded from TAIR [73]. Sequences were aligned with ClustalW2 [74,75]. The theoretical isoelectric points (pI) were calculated with ExPASy Compute $\mathrm{pI} / \mathrm{Mw}$ tool [76]. Disulfide bridges were predicted with EDBCP tool [77-79]. Phylogenetic analyses were performed with CLC Main Workbench 6.6.2 (CLC bio, Aarhus Denmark) [80] and Mega5. The pylogentetic tree was generated with the "Create Tree" function of CLC Main Workbench using the UPGMA algorithm with a bootstrap analysis of 100 replicates, based on an alignment of the HRP amino acid sequences using the "Create Alignment" function with the following settings: Gap open cost: 10.0, Gap extension cost: 1.0, End gap cost: as any other, Alignment: Very accurate (slow). Signal sequences were predicted using SignalP $3.0[81,82]$.

\section{Gene synthesis and heterologous expression in Pichia pastoris}

The codon usages of 14 isoenzymes were optimized for the expression in $P$. pastoris using a novel algorithm (DNA2.0, Menlo Park, CA, USA, Mellitzer et al. manuscript in preparation). Further twelve isoenzymes including allelic variants were optimized using GeneDesigner 1.1.4.1 (DNA2.0) in accordance to the $P$. pastoris codon usage described by Abad et al. [83]. Signal sequence variants were generated by PCR amplification and all HRP genes were cloned into the shuttle vector pPpT4_alpha_S of a newly generated open source expression platform [64]. The vector pPpT4_alpha_S is a basic low-copy (1-5 copies/genome), zeocin $^{\text {тM }}$ resistance based expression vector for efficient secretory expression of heterologous proteins. Sanger sequencing of the plasmids verified successful cloning into the right frame. The linearized expression cassettes were transformed into P. pastoris wild-type CBS7435 based mut ${ }^{\mathrm{s}}$ strain using standard protocols [84], and selected on zeocin ${ }^{\mathrm{TM}}$-containing plates. From each gene, 88 clones were picked to 96-well deep-well plates for cultivation and high-throughput screening of peroxidase activity. Two of the well expressing clones of each isoenzyme were streaked out to single colonies. Four single colonies of each clone were used for re-screening to estimate the reproducibility of the results. All media compositions and cultivation protocols used in this study were as previously described by [85]. Minimal media BMD1\% (buffered minimal media with $1 \%$ dextrose) was supplemented with $5 \mathrm{mM}$ ferrous sulfate heptahydrate (Sigma-Aldrich Handels Gmbh, Vienna, Austria) to ensure sufficient iron supply for heme biosynthesis.

\section{Peroxidase assays}

ABTS (2,2'-azino-bis(3-ethylbenzthiazoline-6-sulfonic acid), TMB (3,3,5'5-tetramethyl benzidine), pyrogallol (1,2,3trihydroxybenzene) and guaiacol (2-methoxyphenol) assays were used to detect peroxidase activity essentially as described in $[3,86,87]$. ABTS assays were performed in $50 \mathrm{mM}$ sodium acetate buffer $\mathrm{pH} 4.5$ with $1 \mathrm{mM}$ ABTS and $0.0026 \%(\mathrm{v} / \mathrm{v}) \mathrm{H}_{2} \mathrm{O}_{2}$. For the TMB stock solution, TMB was dissolved in DMSO to a concentration of 4.16 mM. For the assay solution, TMB stock solution and $30 \%(\mathrm{v} / \mathrm{v}) \mathrm{H}_{2} \mathrm{O}_{2}$ were diluted with $20 \mathrm{mM}$ citrate buffer $\mathrm{pH} 5.5$ to final concentrations of $0.416 \mathrm{mM}$ and $0.006 \%$ $(\mathrm{v} / \mathrm{v})$, respectively. Guaiacol assays were performed in $10 \mathrm{mM}$ sodium phosphate buffer $\mathrm{pH} 7.0$ with $5 \mathrm{mM}$ guaiacol and $0.0009 \%(\mathrm{v} / \mathrm{v}) \mathrm{H}_{2} \mathrm{O}_{2}$. For the pyrogallol assay solution, pyrogallol (Sigma-Aldrich Handels Gmbh, Vienna, Austria) was dissolved in $10 \mathrm{mM}$ potassium phosphate buffer pH6.0 containing $0.027 \%(\mathrm{v} / \mathrm{v}) \mathrm{H}_{2} \mathrm{O}_{2}$ to a concentration of $45 \mathrm{mM}$. For all assays, $15 \mu \mathrm{l}$ cultivation supernatant was mixed with $140 \mu \mathrm{l}$ of the assay solution in a flat-bottom 96-well microtiterplate (Greiner Bio-One $\mathrm{GmbH}$, Frickenhausen, Germany). The reaction kinetics were followed with Spectramax Plus ${ }^{384}$ spectrophotometer and SoftMax ${ }^{\ominus}$ Pro software (Molecular Devices, LLC) for 3-5 min at wavelengths $405 \mathrm{~nm}$ (ABTS), $650 \mathrm{~nm}$ (TMB), $470 \mathrm{~nm}$ (guaiacol) and $420 \mathrm{~nm}$ (pyrogallol). Enzyme activity was calculated using only time points fitting to linear increase of the absorbance $\left(\Delta \mathrm{mAU} \mathrm{min}^{-1}\right)$.

\section{Availability of supporting data}

A. rusticana transcriptome sequencing data is available via EMBL-EBI's European Nucleotide Archive (ENA) under the study accession number PRJEB5793 (http://www.ebi. ac.uk/ena/data/view/PRJEB5793). Nucleotide sequences of the novel identified HRPs have been deposited into 
ENA as well: accession numbers HE963800-HE963825 (http://www.ebi.ac.uk/ena/data/view/HE963800-HE963825). All other supporting data are included as additional files with this manuscript.

\section{Additional files}

Additional file 1: Heatmaps of of the changes in the relative synonymous codon usages ( $\triangle \mathrm{RSCU}$ ) of $\mathrm{A}$ ) all the HRP isoenzymes verified in this study and $B$ ) the known $A$. thaliana peroxidases. Each column represents one codon indicated along the bottom, each row one isoenzyme marked to the right side of the row. Isoenzymes are clustered by their codon usage similarity. Green cells correspond to underrepresented codons, red cells to overrepresented codons. Missing codons are marked with a grey cell.

Additional file 2: Alignment of the amino acid sequences of the HRP isoenzymes.

Additional file 3: BLASTP of respective full length HRP amino acid sequence against non-redundant protein sequences $(\mathrm{nr})$ database with $A$. thaliana (taxid:3702) as organism.

Additional file 4: Primers used in this study.

\section{Abbreviations}

ABTS: 2,2'-azino-bis(3-ethylbenzthiazoline-6-sulfonic acid); AU: Absorption unit; BLAST: Basic local alignment search tool; BLASTX: Search protein databases using a translated nucleotide query; BMD: Buffered minimal media with dextrose; bp: Base pair; CDD: Conserved domains database; cDNA: Complementary DNA; DMSO: Dimethyl sulfoxide; EST: Expressed sequence tag; gDNA: Genomic DNA; HRP: Horseradish peroxidase; LB: Lysogenous broth; mRNA: messenger RNA; NGS: New generation sequencing; ORF: Open reading frame; PSSM: Position-specific scoring matrix; RIN: RNA integrity number; RSCU: Relative synonymous codon usage; SNV: Single nucleotide variation; tBLASTn: search translated nucleotide databases with a protein query; TE: tris-EDTA; TMB: 3,3',5'5-tetramethyl benzidine.

\section{Competing interests}

AG, FWK, and LN report a patent application (No. 11185833.8 - 2403), owned by Graz University of Technology, which relates to the novel recombinant horseradish peroxidase isoenzymes with improved technological properties described in this work and the authors do not have any objection on the patent right of authorship and ownership. All other authors declare that they have no competing interests.

\section{Authors' contributions}

AG, GGT and LN conceived the study and designed the experiments. LN collected the samples, isolated RNA, manually verified the read composition of the peroxidase contigs, and participated in the bioinformatic analysis. MS and GGT developed a pipeline to discover peroxidase isoenzymes in the contigs and participated in the bioinformatic analysis. LN and FWK verified the genomic sequences, planned the synthetic genes and performed protein expression in Pichia pastoris. AG initiated the project and contributed to the evaluation of the results. LN and GGT drafted the manuscript and all other authors revised it and approved the final version.

\section{Acknowledgements}

We would like to thank Christian Schmid and Christoph Fischer for expert technical assistance. This work was supported by the Austrian Science Fund 'Fonds zur Förderung der wissenschaftlichen Forschung' [FWF Grant W901 DK Molecular Enzymology] and in part by the Austrian Ministry of Science and Research GEN-AU project BIN [FFG Grant 820962]. The ACIB contribution was supported by the Austrian BMWFJ, BMVIT, SFG, Standortagentur Tirol and ZIT through the Austrian FFG-COMET- Funding Program [FFG Grant 824186]. Funding for open access charge: Fonds zur Förderung der wissenschaftlichen Forschung.

\section{Author details}

'Institute of Molecular Biotechnology, Graz University of Technology, Petersgasse 14, $8010 \mathrm{Graz}$, Austria. ${ }^{2}$ Austrian Centre of Industrial Biotechnology (ACIB GmbH), Petersgasse 14, 8010 Graz, Austria. ${ }^{3}$ Institute for Genomics and Bioinformatics, Graz University of Technology, Petersgasse 14 8010 Graz, Austria.

Received: 28 November 2013 Accepted: 18 March 2014 Published: 24 March 2014

\section{References}

1. Veitch NC: Horseradish peroxidase: a modern view of a classic enzyme. Phytochemistry 2004, 65:249-259.

2. Greco O, Rossiter S, Kanthou C, Folkes LK, Wardman P, Tozer GM, Dachs GU: Horseradish peroxidase-mediated gene therapy: choice of prodrugs in oxic and anoxic tumor conditions. Mol Cancer Ther 2001, 1:151-160.

3. Morawski B, Quan S, Arnold FH: Functional expression and stabilization of horseradish peroxidase by directed evolution in Saccharomyces cerevisiae. Biotechnol Bioeng 2001, 76:99-107.

4. Wagner M, Nicell JA: Detoxification of phenolic solutions with horseradish peroxidase and hydrogen peroxide. Water Res 2002, 36:4041-4052.

5. Azevedo AM, Martins VC, Prazeres DMF, Vojinović V, Cabral JMS, Fonseca LP: Horseradish peroxidase: a valuable tool in biotechnology. Biotechnol Annu Rev 2003, 9:199-247.

6. Van de Velde F, van Rantwijk F, Sheldon RA: Improving the catalytic performance of peroxidases in organic synthesis. Trends Biotechnol 2001, 19:73-80.

7. Hoyle MC: High resolution of peroxidase-indoleacetic acid oxidase isoenzymes from horseradish by isoelectric focusing. Plant Physiol 1977, 60:787-793

8. Passardi F, Cosio C, Penel C, Dunand C: Peroxidases have more functions than a Swiss army knife. Plant Cell Rep 2005, 24:255-265.

9. Fujiyama K, Takemura H, Shibayama S, Kobayashi K, Choi JK, Shinmyo A, Takano M, Yamada Y, Okada H: Structure of the horseradish peroxidase isozyme C genes. Eur J Biochem 1988, 173:681-687.

10. Fujiyama K, Takemura H, Shinmyo A, Okada H, Takano M: Genomic DNA structure of two new horseradish-peroxidase-encoding genes. Gene 1990, 89:163-169.

11. Bartonek-Roxå E, Eriksson $H$, Mattiasson B: The cDNA sequence of a neutral horseradish peroxidase. Biochim Biophys Acta 1991, 1088:245-250.

12. Nielsen KL, Indiani C, Henriksen A, Feis A, Becucci M, Gajhede M, Smulevich G, Welinder KG: Differential Activity and Structure of Highly Similar Peroxidases. Spectroscopic, Crystallographic, and Enzymatic Analyses of Lignifying Arabidopsis thaliana Peroxidase A2 and Horseradish Peroxidase A2. Biochemistry 2001, 40:11013-11021.

13. Morita Y, Mikami B, Yamashita H, Lee JY, Aibara S, Sato M, Katsube Y, Tanaka N: Primary and crystal structures of horseradish peroxidase isozyme E5. In Biochemical, Molecular and Physiolgical Aspects of Plant Peroxidase. Edited by Lobarzewski J, Greppin H, Penel C, Gaspar T. Lublin and Geneva: University of M. Curie-Sklodowska and University of Geneva; 1991:81-88.

14. Shannon LM, Kay E, Jow Y, Shannon LXI, Lew JY: Chemistry and Metabolism of Macromolecules: Peroxidase Isozymes from Horseradish Roots: I. Isolation and physical Properties. J Biol Chem 1966, 241:2166-2172.

15. Aibara S, Yamashita H, Mori E, Kato M, Morita Y: Isolation and characterization of five neutral isoenzymes of horseradish peroxidase. J Biochem 1982, 92:531-539.

16. Aibara S, Kobayashi T, Morita Y: Isolation and properties of basic isoenzymes of horseradish peroxidase. J Biochem 1981, 90:489-496.

17. Weber APM, Weber KL, Carr K, Wilkerson C, Ohlrogge JB: Sampling the Arabidopsis transcriptome with massively parallel pyrosequencing. Plant Physiol 2007, 144:32-42.

18. Parchman TL, Geist KS, Grahnen JA, Benkman CW, Buerkle CA: Transcriptome sequencing in an ecologically important tree species: assembly, annotation, and marker discovery. BMC Genomics 2010, 11:180.

19. Sun C, Li Y, Wu Q, Luo H, Sun Y, Song J, Lui EMK, Chen S: De novo sequencing and analysis of the American ginseng root transcriptome using a GS FLX Titanium platform to discover putative genes involved in ginsenoside biosynthesis. BMC Genomics 2010, 11:262.

20. Schmid J, Müller-Hagen D, Bekel T, Funk L, Stahl U, Sieber V, Meyer V: Transcriptome sequencing and comparative transcriptome analysis of the scleroglucan producer Sclerotium rolfsii. BMC Genomics 2010, 11:329. 
21. Wong MML, Cannon $\mathrm{CH}$, Wickneswari R: Identification of lignin genes and regulatory sequences involved in secondary cell wall formation in Acacia auriculiformis and Acacia mangium via de novo transcriptome sequencing. BMC Genomics 2011, 12:342.

22. Brown AP, Kroon JTM, Swarbreck D, Febrer M, Larson TR, Graham I a, Caccamo M, Slabas AR: Tissue-specific whole transcriptome sequencing in castor, directed at understanding triacylglycerol lipid biosynthetic pathways. PLoS One 2012, 7:e30100.

23. Clark SM, Vaitheeswaran V, Ambrose SJ, Purves RW, Page JE: Transcriptome analysis of bitter acid biosynthesis and precursor pathways in hop (Humulus lupulus). BMC Plant Biol 2013, 13:12.

24. Egan AN, Schlueter J, Spooner DM: Applications of next-generation sequencing in plant biology. Am J Bot 2012, 99:175-185.

25. Johnson MTJ, Carpenter EJ, Tian Z, Bruskiewich R, Burris JN, Carrigan CT, Chase MW, Clarke ND, Covshoff S, Depamphilis CW, Edger PP, Goh F, Graham S, Greiner S, Hibberd JM, Jordon-Thaden I, Kutchan TM, Leebens-Mack J, Melkonian M, Miles N, Myburg H, Patterson J, Pires JC, Ralph P, Rolf M, Sage RF, Soltis D, Soltis P, Stevenson D, Stewart CN et al: Evaluating methods for isolating total RNA and predicting the success of sequencing phylogenetically diverse plant transcriptomes. PLoS One 2012, 7:e50226.

26. Schliesky S, Gowik U, Weber APM, Bräutigam A: RNA-Seq Assembly - Are We There Yet? Front. Plant Sci. 2012, 3:220.

27. The IKP Project. http://www.onekp.com.

28. Xiao M, Zhang Y, Chen X, Lee E-J, Barber CJS, Chakrabarty R, DesgagnéPenix I, Haslam TM, Kim Y-B, Liu E, MacNevin G, Masada-Atsumi S, Reed DW, Stout JM, Zerbe P, Zhang Y, Bohlmann J, Covello PS, De Luca V, Page JE, Ro DK, Martin VJJ, Facchini PJ, Sensen CW: Transcriptome analysis based on next-generation sequencing of non-model plants producing specialized metabolites of biotechnological interest. J Biotechno/ 2013, 166:122-134.

29. The PhytoMetaSyn Project. http://www.phytometasyn.ca/.

30. Góngora-Castillo E, Childs KL, Fedewa G, Hamilton JP, Liscombe DK, Magallanes-Lundback M, Mandadi KK, Nims E, Runguphan W, Vaillancourt B, Varbanova-Herde M, Dellapenna D, McKnight TD, O'Connor S, Buell CR Development of transcriptomic resources for interrogating the biosynthesis of monoterpene indole alkaloids in medicinal plant species. PLoS One 2012, 7:e52506.

31. The Medicinal Plant Genomics Resource. http://www.medicinalplantgenomics. msu.edu.

32. Wang T-Y, Chen H-L, Lu M-YJ, Chen Y-C, Sung H-M, Mao C-T, Cho H-Y, Ke H-M, Hwa T-Y, Ruan S-K, Hung K-Y, Chen C-K, Li J-Y, Wu Y-C, Chen Y-H, Chou S-P, Tsai Y-W, Chu T-C, Shih C-C a, Li W-H, Shih M-C: Functional characterization of cellulases identified from the cow rumen fungus Neocallimastix patriciarum $W 5$ by transcriptomic and secretomic analyses. Biotechnol. Biofuels 2011, 4:24.

33. Marchler-Bauer A, Panchenko AR, Shoemaker BA, Thiessen PA, Geer LY, Bryant SH: CDD: a database of conserved domain alignments with links to domain three-dimensional structure. Nucleic Acids Res 2002, 30:281-283.

34. Shah SP, Morin RD, Khattra J, Prentice L, Pugh T, Burleigh A, Delaney A, Gelmon K, Guliany R, Senz J, Steidl C, Holt R a, Jones S, Sun M, Leung G, Moore R, Severson T, Taylor G a, Teschendorff AE, Tse K, Turashvili G, Varhol R, Warren RL, Watson P, Zhao Y, Caldas C, Huntsman D, Hirst M, Marra $\mathrm{M}$ a, Aparicio S: Mutational evolution in a lobular breast tumour profiled at single nucleotide resolution. Nature 2009, 461:809-813.

35. Chepelev I, Wei G, Tang Q, Zhao K: Detection of single nucleotide variations in expressed exons of the human genome using RNA-Seq. Nucleic Acids Res 2009, 37:e106

36. Garg R, Patel RK, Tyagi AK, Jain M: De novo assembly of chickpea transcriptome using short reads for gene discovery and marker identification. DNA Res 2011, 18:53-63.

37. Codon Usage Database. http://www.kazusa.or.jp/codon/cgi-bin/showcodon cgi? species $=3704$.

38. Cirulli ET, Singh A, Shianna KV, Ge D, Smith JP, Maia JM, Heinzen EL, Goedert JJ, Goldstein DB: Screening the human exome: a comparison of whole genome and whole transcriptome sequencing. Genome Biol 2010, 11:R57.

39. Toth AL, Varala K, Newman TC, Miguez FE, Hutchison SK, Willoughby DA, Simons JF, Egholm M, Hunt JH, Hudson ME, Robinson GE: Wasp gene expression supports an evolutionary link between maternal behavior and eusociality. Science 2007, 318:441-444.

40. Vera JC, Wheat CW, Fescemyer HW, Frilander MJ, Crawford DL, Hanski I, Marden JH: Rapid transcriptome characterization for a nonmodel organism using 454 pyrosequencing. Mol Ecol 2008, 17:1636-1647.
41. Novaes E, Drost DR, Farmerie WG, Pappas GJ, Grattapaglia D, Sederoff RR, Kirst M: High-throughput gene and SNP discovery in Eucalyptus grandis, an uncharacterized genome. BMC Genomics 2008, 9:312.

42. Pop M, Salzberg SL: Bioinformatics challenges of new sequencing technology. Trends Genet 2008, 24:142-149.

43. Natarajan P, Parani M: De novo assembly and transcriptome analysis of five major tissues of Jatropha curcas L. using GS FLX titanium platform of 454 pyrosequencing. BMC Genomics 2011, 12:191.

44. Huse SM, Huber JA, Morrison HG, Sogin ML, Welch DM: Accuracy and quality of massively parallel DNA pyrosequencing. Genome Bio/ 2007, 8:R143.

45. Hale MC, McCormick CR, Jackson JR, Dewoody JA: Next-generation pyrosequencing of gonad transcriptomes in the polyploid lake sturgeon (Acipenser fulvescens): the relative merits of normalization and rarefaction in gene discovery. BMC Genomics 2009, 10:203.

46. Delker C, Pöschl Y, Raschke A, Ullrich K, Ettingshausen S, Hauptmann V, Grosse I, Quint M: Natural variation of transcriptional auxin response networks in Arabidopsis thaliana. Plant Cell 2010, 22:2184-2200.

47. Alonso-Blanco C, Aarts MGM, Bentsink L, Keurentjes JJB, Reymond M, Vreugdenhil D, Koornneef $\mathrm{M}$ : What has natural variation taught us about plant development, physiology, and adaptation? Plant Cell 2009, 21:1877-1896.

48. Wright F: The "effective number of codons" used in a gene. Gene 1990, $87: 23-29$.

49. Gouy M, Gautier C: Codon usage in bacteria: correlation with gene expressivity. Nucleic Acids Res 1982, 10:7055-7074.

50. Ikemura T: Codon usage and tRNA content in unicellular and multicellular organisms. Mol Biol Evol 1985, 2:13-34.

51. Sharp PM, Matassi G: Codon usage and genome evolution. Curr Opin Genet Dev 1994, 4:851-860.

52. Bulmer M: The Selection-Mutation-Drift Theory of Synonymous Codon Usage. Genetics 1991, 129:897-907.

53. Li WH: Models of nearly neutral mutations with particular implications for nonrandom usage of synonymous codons. J Mol Evol 1987, 24:337-345.

54. Carels N, Bernardi G: The compositional organization and the expression of the Arabidopsis genome. FEBS Lett 2000, 472:302-306.

55. Carels N, Bernardi G: Two classes of genes in plants. Genetics 2000, 154:1819-1825.

56. Vinogradov AE: DNA helix: the importance of being GC-rich. Nucleic Acids Res 1838-1844, 2003:31.

57. Zhang L, Kasif S, Cantor CR, Broude NE: GC/AT-content spikes as genomic punctuation marks. Proc Natl Acad Sci U S A 2004, 101:16855-16860.

58. Jabbari K, Bernardi G: CpG doublets, CpG islands and Alu repeats in long human DNA sequences from different isochore families. Gene 1998, 224:123-127.

59. Galtier N, Piganeau G, D. M, Duret L: GC-Content Evolution in Mammalian Genomes: The Biased Gene Conversion Hypothesis. Genetics 2001, 159:907-911.

60. Mouchiroud D, D'Onofrio G, Aïssani B, Macaya G, Gautier C, Bernardi G: The distribution of genes in the human genome. Gene 1991, 100:181-187.

61. Cosio C, Dunand C: Specific functions of individual class III peroxidase genes. J Exp Bot 2009, 60:391-408.

62. Rayko E, Jabbari K, Bernardi G: The evolution of introns in human duplicated genes. Gene 2006, 365:41-47.

63. Welinder KG: Covalent structure of the glycoprotein horseradish peroxidase (EC 1.11.1.7). FEBS Lett 1976, 72:19-23.

64. Näätsaari L, Mistlberger B, Ruth C, Hajek T, Hartner FS, Glieder A: Deletion of the Pichia pastoris KU70 homologue facilitates platform strain generation for gene expression and synthetic biology. PLOS One 2012, 7:e39720.

65. Marchler-Bauer A, Lu S, Anderson JB, Chitsaz F, Derbyshire MK, DeWeese-Scott C, Fong JH, Geer LY, Geer RC, Gonzales NR, Gwadz M, Hurwitz DI, Jackson JD, Ke Z, Lanczycki C, Lu F, Marchler GH, Mullokandov M, Omelchenko MV, Robertson CL, Song JS, Thanki N, Yamashita RA, Zhang D, Zhang N, Zheng C, Bryant SH: CDD: a Conserved Domain Database for the functional annotation of proteins. Nucleic Acids Res 2011, 39:D225-D229.

66. Camacho C, Coulouris G, Avagyan V, Ma N, Papadopoulos J, Bealer K, Madden TL: BLAST+: architecture and applications. BMC Bioinf 2009, 10:421.

67. Shyamala V, Ferro-Luzzi Ames G: Genome walking by single-specific-primer. Gene 1989, 84:1-8.

68. The European Molecular Biology Laboratory (EMBL). http://www.ebi.ac.uk/embl/.

69. Puigbò P, Bravo IG, Garcia-Vallve S: CAlcal: a combined set of tools to assess codon usage adaptation. Biol Direct 2008, 3:38. 
70. CAlcal Server. http://genomes.urv.es/CAlcal/.

71. Tamura K, Peterson D, Peterson N, Stecher G, Nei M, Kumar S: MEGA5: molecular evolutionary genetics analysis using maximum likelihood, evolutionary distance, and maximum parsimony methods. Mol Biol Evol 2011, 28:2731-2739.

72. Molecular Evolutionary Genetics Analysis (MEGA) software. http://www.megasoftware.net/.

73. The Arabidopsis Information Resource (TAIR). http://www.arabidopsis.org/.

74. Higgins DG, Thompson JD, Gibson TJ: Using CLUSTAL for multiple sequence alignments. Methods Enzym. 1996, 266:383-402.

75. CLUSTALW2. http://www.ebi.ac.uk/Tools/msa/clustalw2/.

76. ExPASy Compute pl/Mw tool. http://web.expasy.org/compute_pi/.

77. Cheng J, Saigo H, Baldi P: Large-scale prediction of disulphide bridges using kernel methods, two-dimensional recursive neural networks, and weighted graph matching. Proteins 2006, 62:617-629.

78. Lippi M, Passerini A, Punta M, Rost B, Frasconi P: MetalDetector: a web server for predicting metal-binding sites and disulfide bridges in proteins from sequence. Bioinformatics 2008, 24:2094-2095.

79. Ensemble-based Disulfide Bonding Connectivity Pattern prediction server. http://biomedical.ctust.edu.tw/edbcp/.

80. CLC bio: CLC Main Workbench 6.6.2. http://www.clcbio.com.

81. Bendtsen JD, Nielsen H, von Heijne G, Brunak S: Improved prediction of signal peptides: SignalP 3.0. J Mol Biol 2004, 340:783-795.

82. SignalP 3.0 Server. http://www.cbs.dtu.dk/services/SignalP/

83. Abad S, Kitz K, Hörmann A, Schreiner U, Hartner FS, Glieder A: Real-time PCR-based determination of gene copy numbers in Pichia pastoris. Biotechnol J 2010, 5:413-420.

84. Lin-Cereghino J, Wong WW, Xiong S, Giang W, Luong LT, Vu J, Johnson SD, Lin-Cereghino GP: Condensed protocol for competent cell preparation and transformation of the methylotrophic yeast Pichia pastoris. Biotechniques 2005, 38:44-48.

85. Weis R, Luiten R, Skranc W, Schwab H, Wubbolts M, Glieder A: Reliable high-throughput screening with Pichia pastoris by limiting yeast cell death phenomena. FEMS Yeast Res 2004, 5:179-189.

86. Ryan BJ, O'Fágáin C: Arginine-to-lysine substitutions influence recombinant horseradish peroxidase stability and immobilisation effectiveness. BMC Biotechnol 2007, 7:86.

87. Morawski B, Lin Z, Cirino P, Joo H, Bandara G, Arnold FH: Functional expression of horseradish peroxidase in Saccharomyces cerevisiae and Pichia pastoris. Protein Eng 2000, 13:377-384.

doi:10.1186/1471-2164-15-227

Cite this article as: Näätsaari et al:: Peroxidase gene discovery from the horseradish transcriptome. BMC Genomics 2014 15:227.

\section{Submit your next manuscript to BioMed Central and take full advantage of:}

- Convenient online submission

- Thorough peer review

- No space constraints or color figure charges

- Immediate publication on acceptance

- Inclusion in PubMed, CAS, Scopus and Google Scholar

- Research which is freely available for redistribution

Submit your manuscript at www.biomedcentral.com/submit
C Biomed Central 